\title{
Critical Success Factors for Competitive Advantage in Iranian Pharmaceutical Companies: A Comprehensive MCDM Approach
}

\author{
Amir Karbassi Yazdi $\left(\mathbb{D},{ }^{1}\right.$ Farhan Muhammad Muneeb $\mathbb{D D}^{2},{ }^{2}$ Peter Fernandes Wanke $(\mathbb{D})^{3}$

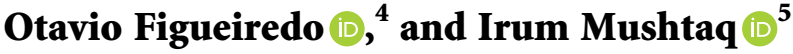 \\ ${ }^{1}$ Young Researchers and Elite Club, South Tehran Branch, Islamic Azad University, Tehran, Iran \\ ${ }^{2}$ School of Management, Xi'an Jiaotong University, Xi'an, Shaanxi, China \\ ${ }^{3}$ Center for Logistics Studies, COPPEAD-The Graduate School of Business Administration, Federal University of Rio de Janeiro, \\ Rio de Janeiro, Brazil \\ ${ }^{4}$ COPPEAD Institute of Administration, Federal University of Rio de Janeiro, Rio de Janeiro, Brazil \\ ${ }^{5}$ School of Business Administration, Qurtuba University of Science and Information Technology, \\ D. I. Khan Campus, Peshawar, Pakistan
}

Correspondence should be addressed to Amir Karbassi Yazdi; st_a_karbassiyazdi@azad.ac.ir

Received 15 September 2020; Revised 12 March 2021; Accepted 30 March 2021; Published 9 April 2021

Academic Editor: Fotios Georgiades

Copyright (c) 2021 Amir Karbassi Yazdi et al. This is an open access article distributed under the Creative Commons Attribution License, which permits unrestricted use, distribution, and reproduction in any medium, provided the original work is properly cited.

\begin{abstract}
The unprecedented COVID-19 outbreak strengthened the critical manifestation of the rapid development vs. survival for pharmaceutical companies, deploying strategic conduct worldwide. This study therefore explores the endogenous relationship among pharmaceutical companies' manufacturing strategy and their performance indicators within the ambit of creating a long-lasting competitive advantage in turbulent times. Very often, it is not possible to launch a cause-effect relationship between performance and their drivers. To achieve this end, multiple-criteria decision-making (MCDM) techniques are employed in a hybrid fashion in this study. The notion has simultaneously ranked critical success factors (CSFs) in the manufacturing strategy and performance indicators in the limelight of managerial perceptions, while controlling the inherent bias concerning the causality direction in the ambit of these two entrenched concepts. A case study on the Iranian pharmaceutical companies is piloted to demonstrate this hybrid-fashion multifarious approach. Overall, the results revealed the most pertinent CSFs that reached superior-performance echelons in the Islamic Republic of Iran.
\end{abstract}

\section{Introduction}

Worldwide companies are strategically involved in reaching distinctive echelons of quality, cost, time, and operational flexibility simultaneously [1-5], ensuring restored performance intensities in such a competitive arena [6-8]. More than ever this is quite essential to sustaining a competitive advantage in this ongoing digital age of innovation, translating strategic modernism into epidemiological pressures [9-11]. As stated by numerous authors from diverse research streams over the past decades [12-16], a competitive advantage is interconnected to how manufacturing physical and human resources are deployed, exploited, and jointly managed to construct distinctive competencies and superior performance over time in some feedback loop $[6,8]$. This feedback loop encompasses creating distinct competencies where the reinforcement and formalization of the company's manufacturing strategy plays an ultimate role [17-20]. Besides the apprehension of a continuous improvement vs. development spirit, performance metrics also lean toward substantial light on manufacturing trade-offs and the possible venues for creating innovative, distinctive competencies and strategic refinement $[19,21,22]$. Thus, the competitive advantage would be sustained by cornerstone methods, procedures, and metrics that could provide robust, firm performance and indicate strategic paths during such turbulent times [23-28]. 
As a matter of fact, on the one hand, business executives pursue competitive advantages and new strategic venues through cautious speculations in developing and/or acquiring novel methods and procedures, capital assets, and strategic HR programs in order to achieve threshold performance [5, 19-21, 29-33]. The development of new strategic manufacturing venues pushes emerging firms towards groundbreaking strategic exploration-exploitation of knowledge and information $[34,35]$, the bonding of manufacturing and overall corporate strategy, and the dissemination and deployment of these innovations throughout the various levels of the company [21, 27, 31, 36-38]. Prior studies focused on the positive feedback loops between creating distinctive competencies and measuring performance after reaching and sustaining competitive advantages in manufacturing $[22,26$, 27, 39-43]. One inclusive framework of manufacturing and corporate strategy proposed by Plates refers to "a configuration of conclusions, linking organizational and operational tasks-to govern the competency and skills to the developed system-to stipulate exactly in what way it will function, to encounter a complete system of these important intentions which are dependable with the whole corporate purposes." [44].

Despite the prominent role that can be enjoyed by manufacturing within the ambit of corporate strategy, manufacturing strategies are frequently conceptualized as a business unit that enhances operational strengths $[36,40,45-52]$ and consumes physical, financial, and human resources expressed in terms of performance metrics that characteristically comprise cost, quality, and lead time. These endogenous relationships between manufacturing strategy and performance indicators can be symbolized as the critical success factors-CSFs [52-56].

In accordance with the theory and literature, this study concentrated on ancient pharmacy firms working in the Islamic Republic of Iran, namely, Production Pharmacies in Iran dating back to Avicenna [57]. In the deep-rooted, ancient cultural heritage, Iranian physicians made pharmacy by practicing botanical medicine and delivered a remedy to their societies in multifarious ways [58]. With the development of advanced technologies, pharmacy fundamentals were transferred from botanical medicine to chemical medicine, and as a consequence, large corporations attempted to restructure the Iranian artisan technology of producing medicines into modern assembly lines, promoting medicines by themselves [58]. Besides, these corporations created $\mathrm{R} \& \mathrm{D}$ sectors to enhance their chemical production and exploit valuable synergies amid new pharmacy and botanical medicine as a strategic approach to gain esteem from society. In this paper, a strategic attempt is made to confine the most noteworthy CSFs that should be taken into legitimate reasoning by pharmaceutical companies. This is deemed necessary as no company possesses unlimited resources to split among different performance drivers. Therefore, these CSFs must be ranked systematically in such turbulent times as the COVID-19 pandemic. However, distinct methods could be pragmatic with filtering and ranking CSFs with a novel research stream of MCDMs based on a ranked relative importance from the most critical factor to the least. The advantages of such approaches are correlated to a shorter computational time and ranking stability to variations in managerial preferences.

Beyond the above considerations, this study makes substantial contributions as it aims to identify and rank the CSFs for competitive advantage in Iranian pharmaceutical companies utilizing a hybrid multiple-criteria decision-making (MCDM) method that can disentangle the endogenous relationships between manufacturing strategy and performance indicators while allowing appropriate ranking of time needed for CSFs in this industry. Second, this study contributes to the extensive literature based on the MCDM method and techniques by focusing on endogenous relationships between manufacturing competence and performance indicators [59]. Hence, from the above reasoning, the research questions of this study can be formalized as follows:

RQ1: what CSFs are determinants to competitive advantages for Iranian pharmaceutical companies?

RQ2: what lessons can be derived from the companies in Iran that have implemented pharmaceutical best practices?

This paper is structured as follows. Section 2 is a literature review of the different aspects of competitive advantages in manufacturing offered with a contextual setting in the Iranian pharmaceutical industry. Subsequently, the methods are presented in Section 3 with the results being analyzed in Section 4. Finally, the conclusions and managerial implications are given in Section 5.

\section{Literature Review}

2.1. Building a Competitive Advantage from Manufacturing Strategy and Performance Indicators. Competitive advantage positions are often built based on the three pillars of operational superiority, consumer sensitivity, and product control [47], which are frequently apprehended as best practices or a scheme to harvest a manufacturing policy by classifying and employing existing best manufacturing beliefs, procedures, and the corporate representations for advancing the entire business [60-63]. Originally, the manufacturing strategy was self-evident [64, 65]. Skinner argued that the manufacturing strategy could play a significant role in the performance of organizations [13]. Numerous studies further developed and tested the propositions [66-69]. In fact, the endogenous relationship between manufacturing strategy and performance indicators is a frequent research object. For instance, Swamidass and Newell indicated that manufacturing superiority is accompanied by a virtuous cycle of performance indicators [66]. Further works have corroborated this endogenous relationship [17, 19, 22, 24, 26-28, 39-42, 61, 66, 67, 70-74].

The knowledge-based economy opened a new paradox for building a competitive advantage based on high-tech development and strategic human capabilities, scheming new productive chains grounded on data analytics and online information [75-81]. However, the manufacturing strategy and performance indicators that have a link and a role in building up a competitive advantage have been scarcely revisited in the digital era [82-89]. As argued by [27, 90], the 
links between manufacturing strategy and performance indicators have been scarcely analyzed vis-à-vis how each CSF parallels each other [91]. Thus, this research gap is addressed by a hybrid MCDM approach that can disentangle the feedback relationship between manufacturing strategy and performance indicators (CSFs) while establishing an unbiased ranking.

Despite all the above reasoning, several companies pursue to increase their performance to earn more profit and loyalty from customers. For achieving these objectives, companies spend many scarce resources such as time, budget, strategic HR practices, etc., but many fail to reach such crucial targets because they do not distinguish how and when they can systematically accomplish them and only spend rare resources. For this reason, widespread knowledge about the returns of CSFs for getting the best competitive advantage from firms is crucial [81, 92]. Hence, a focus on these CSFs leads to the success of companies, but in the first step, all CSFs must be considered. This research attempts to collect all CSFs of competitive advantages and then to customize them for pharmacy companies in Iran. All these CSFs have a cause-and-effect relationship and must be considered in evaluating firms, as presented in Table 1.

\subsection{Application of MCDM Models. As regards the MCDM} models, two different approaches merit attention $[38,93]$. In the first approach, the weights of alternatives are explicitly calculated, and then alternatives will be ranked based on these weights. For instance, the Analytical Hierarchy Process (AHP), Analytical Network Process (ANP), and Measuring Attractiveness through a Categorical-Based Evaluation Technique (MACBETH) are examples of this approach. In the second approach, alternative ranking is based on a decision matrix where weights may not be implicit such as Complex Proportional Assessment (COPRAS), Technique for Order of Preference by Similarity to Ideal Solution (TOPSIS), Vlse Kriterijuska Optimizacija I Komoromisno Resenje (VIKOR), Evaluation by an Area-Based Method of Ranking (EAMR), and so on. Hence, ancillary pairwise methods should be used for determining primary weights $[36,104]$. The drawbacks of both approaches are twofold: first, when the number of criteria is larger than the number of alternatives, yielding nonacceptable consistency rates. The other drawback is related to processing time if pairwise comparisons increase more than proportionally with the criteria.

Biswas [94] demonstrated how MCDM methods in India measured healthcare supply chain performance. Factors used in this research were the sale, earnings before interest, cash, liability, cost of goods sold, average time elapsed between cash and disbursement, and collection, prioritized by PIPRECIA CoCoSo, MABAC, and MARCOS methods for measuring healthcare performance. Esfahani et al. [95] showed how to evaluate an MIS in a public hospital by using MCDM methods according to three dimensions (technology, organization, and human) and subcriteria DEMATEL and ANP methods. Sumrit [96] applied CSFs management inventory in healthcare by MCDM methods in an
TABLE 1: CSFs of competitive advantage.

\begin{tabular}{lc}
\hline Critical success factors & References \\
\hline Formal strategy planning & {$[43]$} \\
New technology & {$[1,43]$} \\
Manufacturing strategy & {$[1,43]$} \\
Modularization of production & {$[43]$} \\
Manufacturing involvement & {$[43]$} \\
Supplier involvement & {$[43]$} \\
Product specification & {$[43]$} \\
Product capability & {$[1,43]$} \\
On-time new product launch & {$[1,43]$} \\
Product innovation & {$[43]$} \\
Customer support & {$[43]$} \\
Infrastructural organization & {$[43]$} \\
Cost & {$[2,30,47,54,81,83]$} \\
Quality & {$[2,30,47,54,81,83]$} \\
Delivery & {$[2,30,47,54,81,83]$} \\
Flexibility & {$[2,30,47,54,81,83]$} \\
Customer satisfaction & {$[2,30,47,54,81,83]$} \\
\hline
\end{tabular}

uncertainty environment. Fuzzy Delphi extracted 18 CSFs, and then grey-DEMATEL relations among these factors were illustrated. Stevic et al. [97] measured sustainable supplier selection by the MARCOS method in the healthcare industry. Three criteria and 37 subcriteria have been considered for supplier selection by the MARCOS method. Emec et al. [98] used MCDM methods for medical supplier selection related to quality, cost, time, brand, technical service, customer representative, and diversity, which are factors that ranked four companies by AHP and fuzzy VIKOR. Chang et al. [99] demonstrated hybrid MCDM methods for evaluating the green biopharmaceutical industry. Twenty-five factors were considered for evaluating 5 alternatives with Best-Worst Method (BWM) and fuzzy TOPSIS. Hasani and Mokhtari [100] implemented dynamic network fuzzy DEA and MCDM methods in the healthcare service industry. Hospital reputation, patient satisfaction, service quality, and social responsibility were the factors of this research. Then, a healthcare system is evaluated based on a dynamic network, DEA, FDEMATEL, and BWM. Table 2 shows the previous research studies.

2.3. Research Gap. The gap in this research is motivated by the epistemic uncertainty regarding the cause-effect relationships between better performance in pharmaceutical companies and their underlying drivers. Unlike previous research, a hybrid approach based on Delphi's combined use, SWARA, and Additive Ratio Assessment (ARAS) methods is proposed here to filter and rank managerial preferences in a robust fashion, mitigating ranking stability issues due to variations in priorities of collecting different samples of respondents. Hence, sensitivity analyses are performed to verify the reliability and stability of results.

\section{Methods}

3.1. Justification of Selected and Hybrid Models. Although there are different MCDM techniques, each of them has a 
TABLE 2: Summary of methods used in previous research studies.

\begin{tabular}{lc}
\hline Reference & Methods \\
\hline$[100]$ & Fuzzy DEA, dynamic network, FDEMATEL, and \\
{$[99]$} & BWM \\
{$[98]$} & BWM, FTOPSIS \\
{$[97]$} & AHP, FVIKOR \\
{$[96]$} & MARCOS \\
{$[95]$} & Fuzzy Delphi, grey-DEMATEL \\
{$[94]$} & DEMATEL, ANP \\
This & PIPRECIA, CoCoSo, MABAC, and MARCOS \\
research & Delphi, SWARA, and ARAS \\
\hline
\end{tabular}

specific function and is used for specific purposes. In this study, we use the ARAS method, and since this method is a kind of MCDM decision matrix method, it requires initial weight. To obtain the initial weight, decision-making techniques based on pairwise comparison methods should be used. One of them is the SWARA method. This method has some merits such as having a high key role in DMs. Also, the relative importance of each further factor is essential for obtaining each weight of factor. The merits of using ARAS method are that its logic concepts use simple mathematics and its computation is straightforward.

This hybrid method is used in this research for these reasons $[31,101]$.

3.2. Stepwise Weight Assessment Ratio Analysis (SWARA) Method. The SWARA technique is an MCDM method that falls within the first approach, relying on weighted replacements $[102,103]$. This method's advantage is that it does not use pairwise comparisons and it compares one criterion against the others, assigning a unique weight for each criterion. In this method, experts assign weights to all criteria $[38,103]$ and then these criteria are then ranked in descending order, observing the following steps:

Step 1. Items are sorted based on expert inputs from the highest to the lowest importance.

Step 2. Preferences are allocated to the second criterion, and this allocation continues until the end of all criteria. Comparative importance average value, named $S_{j}$, is the ratio of this comparison.

Step 3. $K_{j}$ comparative efficiency for criterion $j$ is computed by

$$
K_{j}= \begin{cases}1, & j=1, \\ S_{j}+1, & j>1 .\end{cases}
$$

Step 4 . The intermediate weights $\left(q_{j}\right)$ for criterion $j$ are recomputed by

$$
q_{j}= \begin{cases}1, & j=1, \\ \frac{K_{j-1}}{K_{j}}, & j>1 .\end{cases}
$$

Step 5. The final weight for criterion $j$ is calculated by $W_{j}=q_{j} / \sum_{k=1}^{n} q_{k}$.

3.3. A Novel Additive Ratio Assessment (ARAS) Method. The novel ARAS method is based on a decision matrix approach, as demonstrated by [38], and falls within the second category of MCDM models. Steps of the ARAS method are given next:

Step 1. Create $M_{d}$ as a decision-making matrix:

$$
X=\left[\begin{array}{ccc}
x_{11} & \cdots & x_{o n} \\
\vdots & \ddots & \vdots \\
x_{m 1} & \cdots & x_{m m}
\end{array}\right],
$$

where $x_{i j}$ reveals the value for alternative $i$ for criterion $j ; n$ represents the number of alternatives, and $m$ is the number of criteria. A given performance value $x_{o j}$ is the optimal value of criterion $j$.

Step 2. Optimal value of criterion $j$ is demonstrated as follows:

$x_{o j}=\max _{i} x_{i j}$, if $\max _{i} x_{i j}$ is preferable

$x_{o j}=\min _{i}^{i} x_{i j}^{*}$, if $\min _{i}^{i} x_{i j}^{*}$ is preferable

Step 3. Normalized matrix value is

$$
\bar{X}=\left[\begin{array}{ccc}
x_{11} & \cdots & x_{0 n} \\
\vdots & \ddots & \vdots \\
x_{m 1} & \cdots & x_{m m}
\end{array}\right] .
$$

If the preferable values are maximum, the normalized criteria are demonstrated as follows:

$$
\begin{aligned}
& x_{i j}=\frac{x_{i j}}{\sum_{i=0}^{m} x_{i j}}, \\
& x_{i j}=\frac{1}{x_{i j}^{*}} ; \\
& \overline{x_{i j}}=\frac{x_{i j}}{\sum_{i=0}^{m} x_{i j}} .
\end{aligned}
$$

Step 4. Weighted matrix is given next:

$$
\widehat{X}=\left[\begin{array}{ccc}
\widehat{x_{01}} & \cdots & \widehat{x_{0 n}} \\
\vdots & \ddots & \vdots \\
\widehat{x_{m 1}} & \cdots & \widehat{x_{m m}}
\end{array}\right] .
$$

The normalized-weighted value for all criteria is demonstrated as follows:

$$
\widehat{x_{i j}}=\overline{x_{i j}} w_{j} \text {. }
$$

Step 5. Calculate the optimal value of the function:

$$
S_{i}=\sum_{j=1}^{n} \widehat{x_{i j}} .
$$


Step 6. In this last step, the utility degree can be successfully computed:

$$
K_{i}=\frac{S_{i}}{S_{O}} .
$$

3.4. Research Methodology Procedure. The hybrid MCDM approach developed in this research is presented next. Readers should note that in Phase I, relevant CSFs are identified first from previous studies, while in Phase II, the Delphi method is used to filter the CSFs of the manufacturing strategy and performance indicators. In Phase III, the SWARA method is employed to determine the primary weights of these CSFs $[6,38]$. These weights serve as inputs for the ARAS method in Phase IV to compute the final ranking of the pharmaceutical companies as per the preferences expressed by managers in terms of each CSF.

These significant steps are depicted in Figure 1.

3.5. Sampling. There are 25 pharmaceutical companies listed in the Iranian stock market whose data is easily accessed to identify experts/executives to be interviewed. Eleven companies responded favorably concerning participating in this research, which is in line with the Delphi formula that suggests the number of experts to vary between 5 and 15 respondents. Computations were performed using MS Excel. The detailed information of these experts is listed in Table 3.

3.6. Customized CSFs. In practice, the Delphi method examines unidentified specialist opinions and arranges their arguments and reactions in a printed, precise framework. This method enables advanced group conclusion-making by observing diverse interpretations resulting from face-to-face communication [103-106]. The Delphi method is considered a cornerstone tool for filtering CSFs based on expert opinions [14]. In this research, the questionnaire was developed from the CSFs collected in Table 1, while experts give their opinion based on a 5-point Likert scale. When the average score for all managerial preferences is less than four, that given CSF is eliminated [66].

In this research, 17 CSFs were successfully filtered based on the Delphi method. Table 4 reports the computations of their average scores. Five CSFs related to new technology, modularization of production, product specification, product competence, and product presentation were eliminated within the specific period, possibly due to limitations imposed by economic sanctions. It is interesting to note that the CSFs eliminated were all related to manufacturing strategy, thus suggesting an overrepresentation of CSFs related to performance indicators in the final CSF list, as depicted in Table 5.

\section{Case Study}

Columbus Langdell, the first dean of the law school, set the ball rolling in 1870 [107]. Case study research continues to be poorly understood in psychology, sociology, anthropology, political science, and epidemiology since the strengths and weaknesses of case study research, and especially how to practice it well, still need clarification [108]. Case study is defined as a strategic method, methodology, or research design $[109,110]$. This study chose a case study in the Islamic Republic of Iran that was primarily dedicated to ancient pharmaceutical companies to find various legitimate matrices in confirming critical success factors of manufacturing strategy during turbulent times of the COVID-19 pandemic.

4.1. Contextual Setting of the Pharmaceutical Industry in the Islamic Republic of Iran. This study found 25 pharmaceutical companies that are officially listed on the Islamic Republic of Iran's stock markets. Their overall value accounts for only $2 \%$ of the stock market of the Islamic Republic of Iran. This suggests that firms in this industry present a smaller scale when compared to firms of other industries. These companies produce innumerable pharmacy products such as tablets, medicinal draught, ampoules such as antibiotics, and medications such as those for diabetes, anesthesia, skin diseases, heart problems, and mental disorders. The assets of all pharmaceutical companies in the Islamic Republic of Iran are meager except for two companies. Most of these companies need to import raw materials that come from foreign countries with the US economic sanctions against the Islamic Republic of Iran affecting most pharmaceutical companies. In this industry, most of the raw material comes from foreign countries, but due to the US sanctions on transferring money between Iranian banks and international banks, these companies cannot buy raw material. Therefore, they can only produce limited goods for domestic customers based on traditional Iranian pharmacopeia.

4.2. Results. After filtering the CSFs, the first primary weights were obtained based on the SWARA method as presented in Table 6.

Firms were then ranked based on the ARAS decision matrix, as reported in Table 7. Normalized values for their decision matrix are given in Table 8, while the final ranks are shown in Table 9.

4.3. Sensitivity Analysis. There is no harmony on regulating the sensitivity analysis, i.e., the "quality" of a judgment method and the reliability of the results [111, 112]. The sensitivity analysis can be defined as constancy or conduct of the explanation to minor modifications in preferences that arise during the determination procedure [113] or small changes in the values taken for constraints. It is what some researchers reflect as competence multicriteria decision method $[114,115]$. Barron and Schmidt [116] suggested two processes to achieve a sensitivity analysis in multiattribute value models (an approach grounded on entropy and a leastsquares technique). For a specified pair of alternatives, these processes estimate the best option, the closest set of weights that equates their ranking with [117] demonstrating a sensitivity analysis in a decision modeling strategy. 


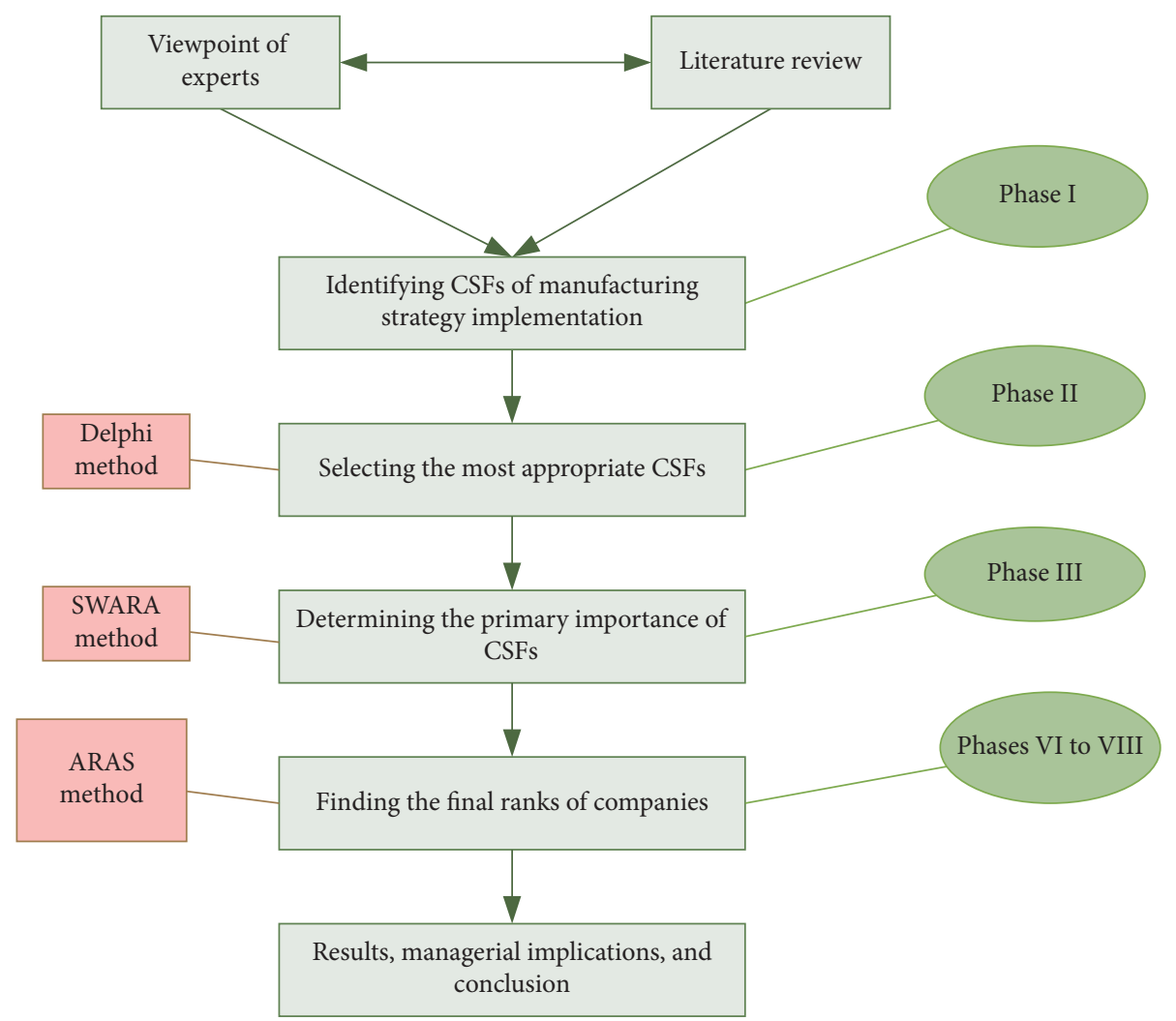

FIGURE 1: Research methodology.

TABle 3: Information of experts.

\begin{tabular}{lcc}
\hline Expert & Education & Experience \\
\hline Expert 1 & Ph.D. & 23 \\
Expert 2 & Ph.D. & 28 \\
Expert 3 & M.S. & 29 \\
Expert 4 & M.D. & 30 \\
Expert 5 & Ph.D. & 27 \\
Expert 6 & M.S. & 26 \\
Expert 7 & M.D. & 27 \\
Expert 8 & Ph.D. & 29 \\
Expert 9 & M.D. & 24 \\
\hline
\end{tabular}

Table 4: Computation of the Delphi method.

\begin{tabular}{|c|c|c|c|c|c|c|c|c|c|c|}
\hline & DM1 & DM2 & DM3 & DM4 & DM5 & DM6 & DM7 & DM8 & DM9 & Average \\
\hline Formal strategy planning & 5 & 4 & 5 & 4 & 3 & 5 & 2 & 5 & 4 & 4.11 \\
\hline New technology & 3 & 2 & 4 & 5 & 2 & 3 & 5 & 2 & 4 & 3.33 \\
\hline Manufacturing strategy & 5 & 5 & 4 & 5 & 4 & 3 & 2 & 5 & 4 & 4.11 \\
\hline Modularization of production & 3 & 4 & 2 & 3 & 5 & 4 & 2 & 3 & 5 & 3.44 \\
\hline Manufacturing involvement & 5 & 4 & 5 & 5 & 3 & 2 & 5 & 4 & 4 & 4.11 \\
\hline Supplier involvement & 5 & 4 & 5 & 4 & 3 & 5 & 5 & 4 & 3 & 4.22 \\
\hline Product specification & 5 & 5 & 5 & 4 & 3 & 2 & 5 & 4 & 2 & 3.89 \\
\hline Product capability & 3 & 2 & 3 & 2 & 4 & 2 & 3 & 2 & 5 & 2.89 \\
\hline On-time new product launch & 3 & 2 & 3 & 4 & 3 & 5 & 3 & 2 & 4 & 3.22 \\
\hline Product innovation & 5 & 4 & 5 & 4 & 2 & 3 & 5 & 4 & 5 & 4.11 \\
\hline Customer support & 5 & 5 & 4 & 4 & 5 & 2 & 3 & 5 & 4 & 4.11 \\
\hline Infrastructural organization & 5 & 5 & 4 & 5 & 5 & 4 & 2 & 3 & 5 & 4.22 \\
\hline Cost & 4 & 4 & 5 & 5 & 4 & 2 & 3 & 5 & 4 & 4.00 \\
\hline Quality & 5 & 5 & 5 & 4 & 5 & 4 & 3 & 2 & 5 & 4.22 \\
\hline Delivery & 5 & 4 & 2 & 3 & 5 & 4 & 5 & 4 & 5 & 4.11 \\
\hline Flexibility & 4 & 4 & 5 & 4 & 5 & 4 & 5 & 2 & 3 & 4.00 \\
\hline Customer satisfaction & 5 & 4 & 5 & 5 & 5 & 4 & 2 & 3 & 5 & 4.22 \\
\hline
\end{tabular}


Table 5: Result of the Delphi method.

\begin{tabular}{lc}
\hline Formal strategy planning & Accept \\
\hline New technology & Reject \\
Manufacturing strategy & Accept \\
Modularization of production & Reject \\
Manufacturing involvement & Accept \\
Supplier involvement & Accept \\
Product specification & Reject \\
Product capability & Reject \\
On-time new product launch & Reject \\
Product innovation & Accept \\
Customer support & Accept \\
Infrastructural organization & Accept \\
Cost & Accept \\
Quality & Accept \\
Delivery & Accept \\
Flexibility & Accept \\
Customer satisfaction & Accept \\
\hline
\end{tabular}

Spearman's rank correlation coefficient test results show that the actual consequence computed using ARAS represents an effective compromise solution concerning other MCDM methods since all significances are less than 0.05 . Table 10 points out the result of the MCDA methods, Table 11 demonstrates the Pearson correlation coefficient test result, and Figure 2 shows a sensitivity analysis.

\section{Discussion and Contributions}

Telemedicine and ancient pharmaceutical firms are trying to develop, manage, and improve competitive advantage through strategic manufacturing. However, manufacturing is challenging in turbulent times of the COVID-19 pandemic [118] for controlling customer orders, market dynamics, insufficient resource setups, government strategies, and turbulent supply issues. Moreover, the successful accomplishment of numerous business activities in pharmaceutical companies endures the paramount survival by deploying strategic conduct and establishing endogenous relationships among companies and a high-technology manufacturing strategy $[49,59]$, translating not only "challenging," but even "grand challenging" situations, especially for the Islamic Republic of Iran. Unzipping this critical spectrum, this study presents a new paradigm of prioritizing manufacturing strategy essential factors of success via MCDM methods, so this decision-making plays a crucial role in reaching a "winwin" scenario through SWARA methods, which is an appropriate technique because specialists can openhandedly deliberate and verbalize their conclusions [101, 119-121]. It does not seem that individual conditions can do anything in apprehension of anticipated perceptions; therefore, the additional investigation can be appropriate for this merging procedure as a malleable method for other situations. In accretion, a recent revision vs. exercise could emphasize a legitimate understanding of other MCDM techniques comprising ARAS, ANP, and PROMETHEE in order to accrue the absolute dream of different consequences [68, 122-124].

The baseline contribution areas are first; this study manifested exploration-exploitation and deliberated all various manufacturing strategy characteristics and CSFs, which becomes incredibly substantial in turbulent times for the Islamic Republic of Iran. Moreover, these CSFs are screening and customizing those based on a structural system named the Delphi method [125, 126]. Second, the hybrid modeling fashion of MCDM methods has been functional to determine the optimum firms based on the CSFs of manufacturing strategy $[26,91]$.

Correspondingly, prior work on manufacturing strategy has been the various strategic theme of gigantic firm deliberation and operations of research interaction in uncertainty and risk environments to acquire sustainable productivity [127]. In this digital era when modernization shows high firm roles, this is when price, excellence, distribution, and novelty management are deep-seated priorities for any firm to boost attractiveness. The presentation dimension of manufacturing strategy is an authoritative vital issue to size the efficiency. Therefore, this research endeavor has been made to evaluate the literature based on manufacturing strategy, noticeably augmenting CSFs, the strategic necessity in turbulent times of the public emergency such as the COVID-19 pandemic. This study characterized CSFs and substantially construed them into advantageous positions. We reason that this study subsidizes a superior indulgence of CSFs linking MCDM methods, which have been extracted from previous investigations. Thus, this study found 17 CSFs from previous research simultaneously related to the core inquiry. Thus, by the exclusionary Delphi method, 5 of them were eradicated in this study and the remaining 12 CSFs were given a critical role position to answer the legitimate answer of RQ1. Besides, to provide and mark RQ2, a foundation based on 12 CSFs, where this study shortlisted 11 pharmacy companies, is evaluated by the ARAS method, a decision matrix method. Thus, our findings revealed that, besides 11 substantial companies, 5 companies are performing planned manufacturing in the Islamic Republic of Iran.

5.1. Managerial Implications. This study sets the MCDM method approach that consents a competitive and generic marketing strategy to be applied in pharmaceutical companies in the Islamic republic of Iran, translating to reach higher competitive advantages during turbulent times of the COVID-19 pandemic. Thus, managers taking such strategic actions could help support such companies to perform healthier in turbulent times [118]. Our work findings offer implications for considering sustainable manufacturing efforts in pharmaceutical companies. The Iranian government attempts to control limited resources to such pharmaceutical companies in turbulent times [118], so it should provide information technology tools and expert systems to perform more sustainable manufacturing productivity. However, the sustained manufacturing development vs. success in pharmaceutical companies is multifariously contingent on capabilities and competencies of agile $\mathrm{R} \& \mathrm{D}$ government management, which is lacking in the Islamic Republic of Iran $[128,129]$. These company managers should regularly check the government $\mathrm{R} \& \mathrm{D}$ to deploy a sustainable manufacturing strategy. 


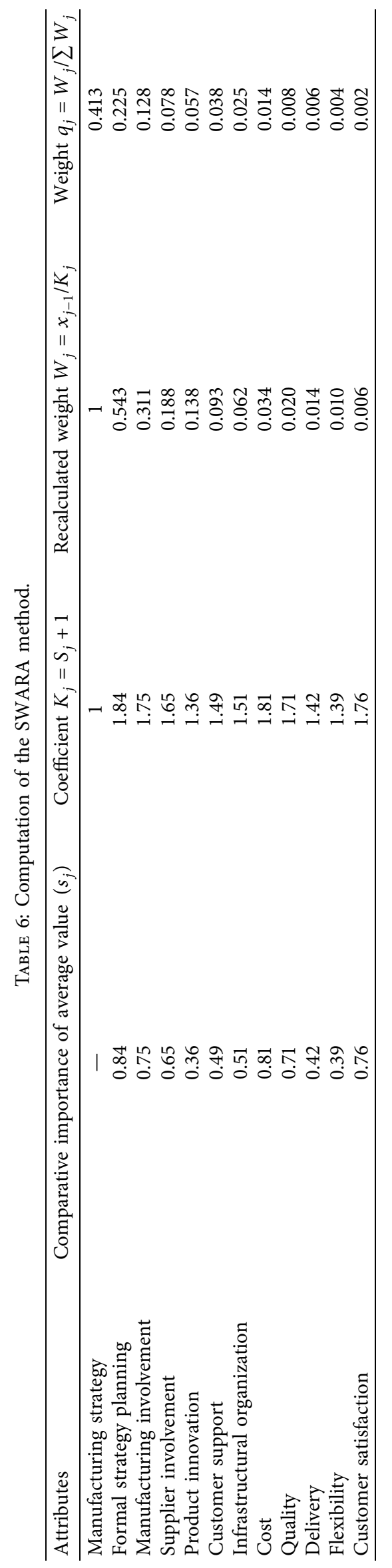




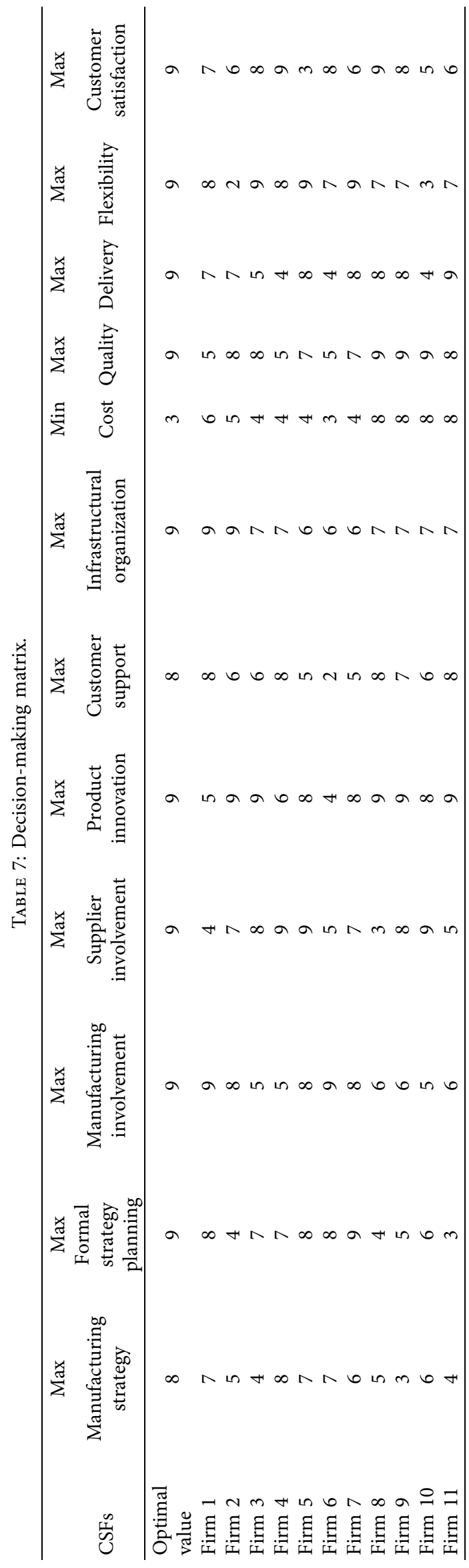




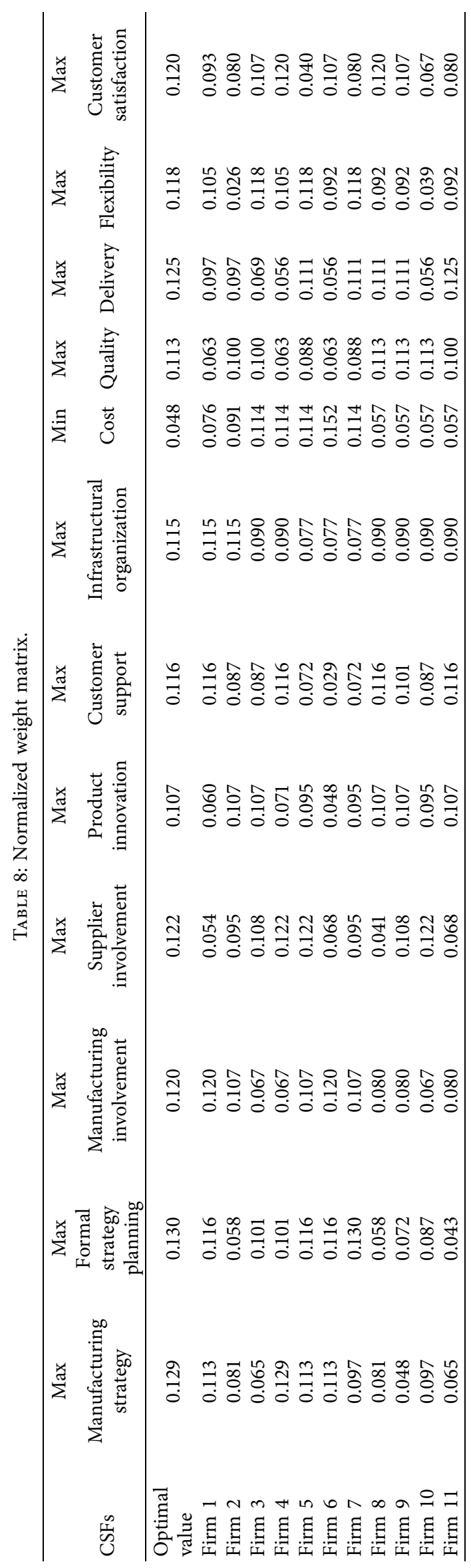




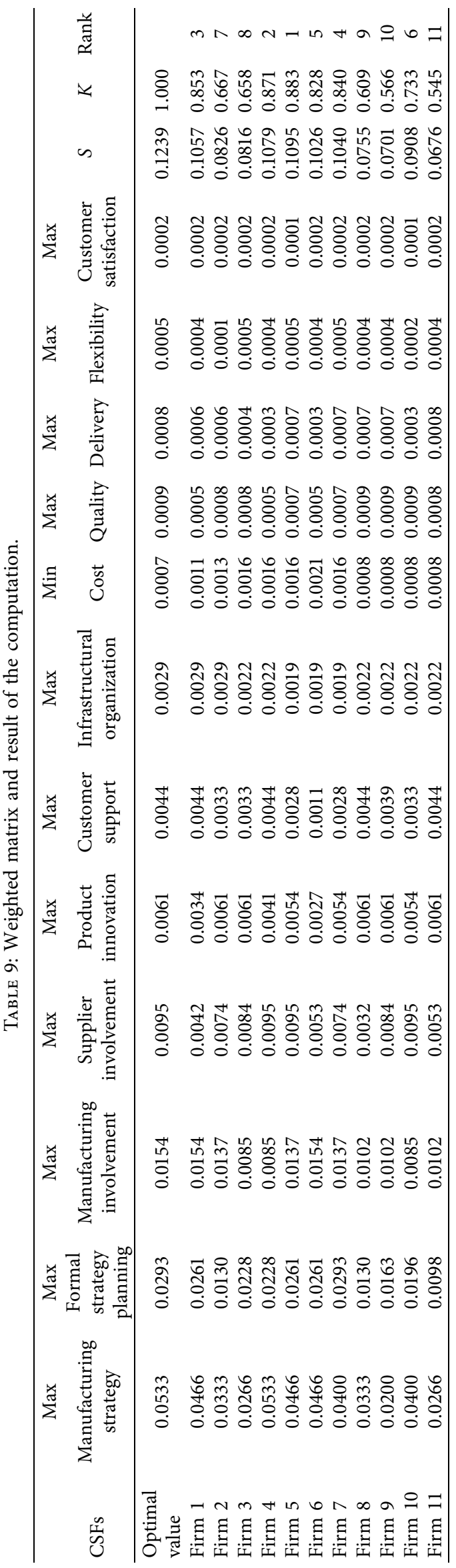


TABLE 10: The result of MCDA methods.

\begin{tabular}{|c|c|c|c|c|c|c|}
\hline & ARAS & TOPSIS & VIKOR & MABAC & CoCoSo & WASPAS \\
\hline Firm 1 & 3 & 3 & 2 & 2 & 1 & 3 \\
\hline Firm 2 & 7 & 7 & 7 & 7 & 5 & 7 \\
\hline Firm 3 & 8 & 8 & 9 & 8 & 6 & 8 \\
\hline Firm 4 & 2 & 2 & 4 & 3 & 4 & 2 \\
\hline Firm 5 & 1 & 1 & 1 & 1 & 3 & 1 \\
\hline Firm 6 & 5 & 4 & 3 & 5 & 7 & 5 \\
\hline Firm 7 & 4 & 5 & 5 & 4 & 2 & 4 \\
\hline Firm 8 & 9 & 9 & 8 & 9 & 9 & 9 \\
\hline Firm 9 & 10 & 10 & 11 & 10 & 10 & 10 \\
\hline Firm 10 & 6 & 6 & 6 & 6 & 8 & 6 \\
\hline Firm 11 & 11 & 11 & 10 & 11 & 11 & 11 \\
\hline
\end{tabular}

TABLE 11: Spearman's correlation test.

\begin{tabular}{lccccc}
\hline ARAS & TOPSIS & VIKOR & MABAC & CoCoSo & WASPAS \\
\hline Significance & 0 & 0 & 0 & 0.001 & 0 \\
Correlation & 0.991 & 0.936 & 0.991 & 0.855 & 1 \\
\hline
\end{tabular}

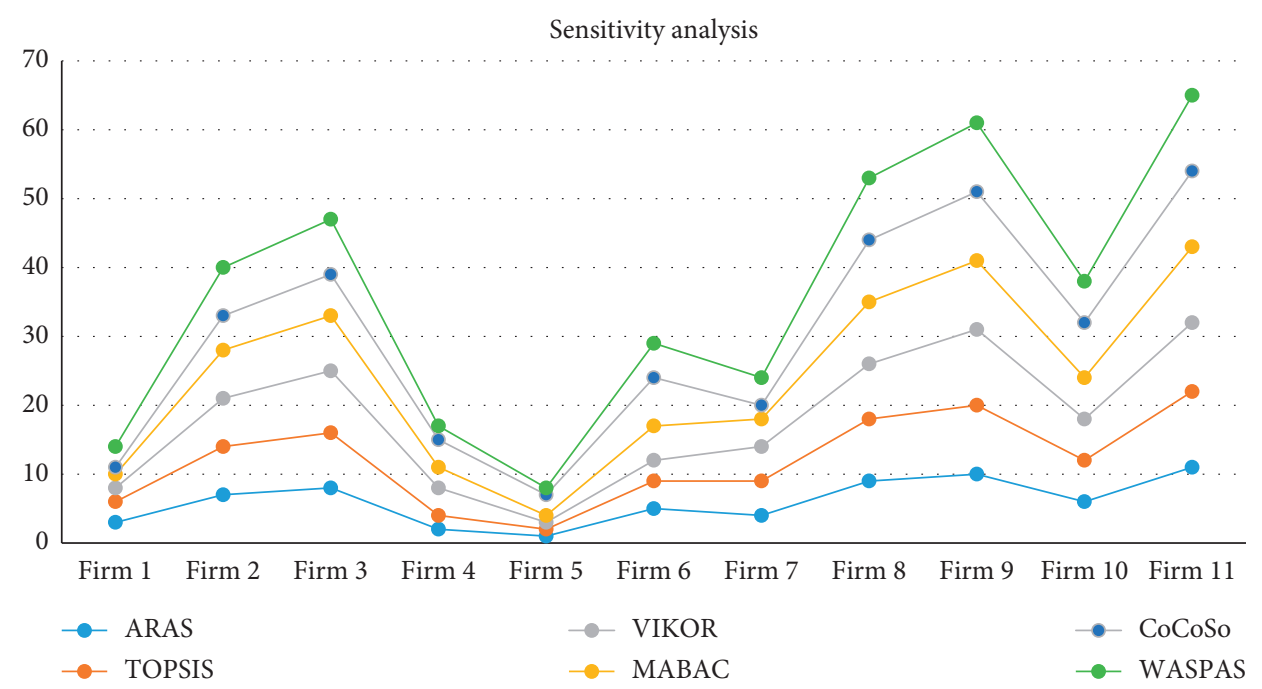

Figure 2: Sensitivity analysis.

5.2. Limitations and Future Research Agendas. Explicit and publicly available decision-making can multifariously further reboot the transparency and accountability of the manufacturing conduct in pharmaceutical companies $[113,115]$. This study is based on 25 pharmaceutical companies listed on the Iranian stock market, which probes this work's highest limitation. It simultaneously can build the forthcoming effort-exertion to exhibit the generalizability of more in-depth data in practical decision-making by using other MCDM method approaches. This study recommends that future exploration-exploitation should be led by emerging a crucial obligation based on performance schemes, translating multinational contrasts of manufacturing strategy with strategic Human Resources Management (HRM) through experimental cross-sectional investigation [130] of pharmaceutical companies by using an MCDM method approach. Besides the Islamic Republic of Iran's current turbulence section environment affecting its severe foreign direct investment [131], this study cannot provide legitimate contextual experiment through MCDM methods even including a detailed limitation. Thus, future deliberation should be recommended to spur multifarious manifestation between cross-sectional studies between China and Iran to raise critical queries [132] such as what CSFs are determinant to competitive advantages in developing vs. emerging economy pharmaceutical companies. Finally, this study helped build a robust sustainable manufacturing strategy and suggested elaborating pharmaceutical companies vs. manufacturing strategy by using other theoretical and statistical lenses for future research agendas.

\section{Data Availability}

The data used to support the findings of this study are available from the corresponding author upon request. 


\section{Conflicts of Interest}

The authors declare that they have no conflicts of interest regarding the publication of this paper.

\section{References}

[1] G. Z. Jia and M. Bai, "An approach for manufacturing strategy development based on fuzzy-QFD," Computers \& Industrial Engineering, vol. 60, no. 3, pp. 445-454, 2011.

[2] S.-C. Hung, S.-W. Hung, and M.-J. J. Lin, "Are alliances a panacea for SMEs? The achievement of competitive priorities and firm performance," Total Quality Management \& Business Excellence, vol. 26, no. 1-2, pp. 190-202, 2015.

[3] M. Presutti, C. Boari, and L. Fratocchi, "Knowledge acquisition and the foreign development of high-tech start-ups: a social capital approach," International Business Review, vol. 16, no. 1, pp. 23-46, 2007.

[4] F. P. Williams, D. E. D’Souza, M. E. Rosenfeldt, and M. Kassaee, "Manufacturing strategy, business strategy and firm performance in a mature industry," Journal of Operations Management, vol. 13, no. 1, pp. 19-33, 1995.

[5] I. J. Orji and S. Wei, "Dynamic modeling of sustainable operation in green manufacturing environment," Journal of Manufacturing Technology Management, vol. 26, no. 8, 2015.

[6] F. M. Muneeb, A. K. Yazdi, P. Wanke, C. Yiyin, and M. Chughtai, "Critical success factors for sustainable entrepreneurship in Pakistani Telecommunications industry: a hybrid grey systems theory/best-worst method approach," Management Decision, vol. 58, no. 11, 2020.

[7] S. Panahi, A. Khakzad, and P. Afzal, "Application of stepwise weight assessment ratio analysis (SWARA) for copper prospectivity mapping in the Anarak region, central Iran," Arabian Journal of Geosciences, vol. 10, no. 22, p. 484, 2017.

[8] M. Parikh, "Knowledge management framework for hightech research and development," Engineering Management Journal, vol. 13, no. 3, pp. 27-34, 2001.

[9] S. Kiridena, M. Hasan, and R. Kerr, "Exploring deeper structures in manufacturing strategy formation processes: a qualitative inquiry," International Journal of Operations and Production Management, vol. 29, no. 4, 2009.

[10] J. A. DiMasi, H. G. Grabowski, and R. W. Hansen, "Innovation in the pharmaceutical industry: new estimates of R\&D costs," Journal of Health Economics, vol. 47, pp. 20-33, 2016.

[11] H. Gupta, S. Kusi-Sarpong, and J. Rezaei, "Barriers and overcoming strategies to supply chain sustainability innovation," Resources, Conservation and Recycling, vol. 161, Article ID 104819, 2020.

[12] H. I. Ansoff, Acquisition Behavior of US Manufacturing Firms, 1946-1965, Vanderbilt University Press, Nashville, TN, USA, 1971.

[13] S. Singh, E. U. Olugu, S. N. Musa, and A. B. Mahat, "Fuzzy-based sustainability evaluation method for manufacturing SMEs using balanced scorecard framework," Journal of Intelligent Manufacturing, vol. 29, pp. 1-18, 2015.

[14] J. Adams, C. Harris, and K. A. Bohley Martin, "Explaining small-business development: a small-business development model combining the maslow and the hayes and wheelwright models," Journal of the Indiana Academy of the Social Sciences, vol. 18, no. 1, p. 4, 2015.

[15] M. Abadi, P. Barham, J. Chen et al., "Tensorflow: a system for large-scale machine learning," in Proceedings of the 12th $\{$ USENIX\} symposium on operating systems design and implementation (\{OSDI\} 16), pp. 265-283, Savannah, GA, USA, November 2016.

[16] P. Milling, F. H. Maier, and D. Mansury, "Impact of manufacturing strategy on plant performance-insights from the international research project: world class manufacturing," 1999.

[17] Y. K. A. A. Migdadi and D. a. S. I. Elzzqaibeh, "The evaluation of green manufacturing strategies adopted by ISO 14001 certificate holders in Jordan," International Journal of Productivity and Quality Management, vol. 23, no. 1, pp. 90-109, 2018.

[18] L. Kogan, D. Papanikolaou, A. Seru, and N. Stoffman, "Technological innovation, resource allocation, and growth*," The Quarterly Journal of Economics, vol. 132, no. 2, pp. 665-712, 2017.

[19] B. B. Flynn and E. J. Flynn, "An exploratory study of the nature of cumulative capabilities," Journal of Operations Management, vol. 22, no. 5, pp. 439-457, 2004.

[20] E. Kazimieras Zavadskas, J. Antucheviciene, and P. Chatterjee, Multiple-criteria Decision-Making (MCDM) Techniques for Business Processes Information Management, Multidisciplinary Digital Publishing Institute, Basel, Switzerland, 2019.

[21] M. A. Ilgin, S. M. Gupta, and O. Battaïa, "Use of MCDM techniques in environmentally conscious manufacturing and product recovery: state of the art," Journal of Manufacturing Systems, vol. 37, pp. 746-758, 2015.

[22] P. M. Swamidass and W. T. Newell, "Manufacturing strategy, environmental uncertainty and performance: a path analytic model," Management Science, vol. 33, no. 4, pp. 509-524, 1987.

[23] H. Mintzberg, "The nature of managerial work," 1973.

[24] S. Devaraj, D. G. Hollingworth, and R. G. Schroeder, "Generic manufacturing strategies and plant performance," Journal of Operations Management, vol. 22, no. 3, pp. 313-333, 2004.

[25] L. M. Corbett, "Manufacturing strategy, the business environment, and operations performance in small low-tech firms," International Journal of Production Research, vol. 46, no. 20, pp. 5491-5513, 2008.

[26] G. J. C. da Silveira and R. S. Sousa, "Paradigms of choice in manufacturing strategy," International Journal of Operations \& Production Management, vol. 30, no. 12, pp. 1219-1245, 2010.

[27] L. Lucianetti, C. J. Chiappetta Jabbour, A. Gunasekaran, and H. Latan, "Contingency factors and complementary effects of adopting advanced manufacturing tools and managerial practices: effects on organizational measurement systems and firms' performance," International Journal of Production Economics, vol. 200, pp. 318-328, 2018.

[28] F. L'Écuyer, L. Raymond, B. Fabi, and S. Uwizeyemungu, "Strategic alignment of IT and human resources management in manufacturing SMEs," International Journal Employee Relations, vol. 41, no. 5, 2019.

[29] M. L. Heine, V. Grover, and M. K. Malhotra, "The relationship between technology and performance: a metaanalysis of technology models," Omega, vol. 31, no. 3, pp. 189-204, 2003.

[30] P. T. Ward and R. Duray, "Manufacturing strategy in context: environment, competitive strategy and manufacturing strategy," Journal of Operations Management, vol. 18, no. 2, pp. 123-138, 2000.

[31] D. Karabasevic, E. K. Zavadskas, Z. Turskis, and D. Stanujkic, "The framework for the selection of personnel based on the SWARA and ARAS methods under uncertainties," Informatica, vol. 27, no. 1, pp. 49-65, 2016. 
[32] M. A. Kaviani, A. K. Yazdi, L. Ocampo, and S. Kusi-Sarpong, "An integrated grey-based multi-criteria decision-making approach for supplier evaluation and selection in the oil and gas industry," Kybernetes, vol. 49, no. 2, 2019.

[33] S. Kusi-Sarpong, H. Gupta, and J. Sarkis, "A supply chain sustainability innovation framework and evaluation methodology," International Journal of Production Research, vol. 57, no. 7, pp. 1990-2008, 2019.

[34] R. G. Schroeder, R. Shah, and D. Peng, The Sand Cone Model Revisited: A New Perspective, Carlson School of Management, University of Minnesota, Minneapolis, MN, USA, 2006.

[35] A. K. Yazdi and M. Haddadi, "Prioritising critical successful factors of knowledge management in insurance companies," International Journal of Operational Research, vol. 31, no. 3, p. 281, 2018.

[36] D. Sardana, M. Terziovski, and N. Gupta, "The impact of strategic alignment and responsiveness to market on manufacturing firm's performance," International Journal of Production Economics, vol. 177, pp. 131-138, 2016.

[37] F. Jalilian, S. M. Hazavehei, A. A. Vahidinia, M. Jalilian, and A. Moghimbeigi, "Prevalence and related factors for choosing self-medication among pharmacies visitors based on health belief model in Hamadan Province, west of Iran," Journal of Research in Health Sciences, vol. 13, no. 1, pp. 81-85, 2013.

[38] J. Dahooie, E. Zavadskas, M. Abolhasani, A. Vanaki, and Z. Turskis, "A novel approach for evaluation of projects using an interval-valued fuzzy additive ratio assessment (ARAS) method: a case study of oil and gas well drilling projects," Symmetry, vol. 10, no. 2, p. 45, 2018.

[39] J. G. Miller and A. V. Roth, "A taxonomy of manufacturing strategies," Management Science, vol. 40, no. 3, pp. 285-304, 1994.

[40] I. Ehie and O. Muogboh, "Analysis of manufacturing strategy in developing countries," Journal of Manufacturing Technology Management, vol. 27, no. 2, 2016.

[41] K. Amoako-Gyampah and M. Acquaah, "Manufacturing strategy, competitive strategy and firm performance: an empirical study in a developing economy environment," International Journal of Production Economics, vol. 111, no. 2, pp. 575-592, 2008.

[42] A. V. Roth and M. Van Der Velde, "Operations as marketing: a competitive service strategy," Journal of Operations Management, vol. 10, no. 3, pp. 303-328, 1991.

[43] I. A. Arana-Solares, C. H. Ortega-Jiménez, R. Alfalla-Luque, and J. L. Pérez-Díez de los Ríos, "Contextual factors intervening in the manufacturing strategy and technology management-performance relationship," International Journal of Production Economics, vol. 207, pp. 81-95, 2019.

[44] P. J. G. Pineda, J. J. H. Liou, C.-C. Hsu, and Y.-C. Chuang, "An integrated MCDM model for improving airline operational and financial performance," J. Air Transp. Manag.vol. 68, pp. 103-117, 2018.

[45] T. H. Netland, "Critical success factors for implementing lean production: the effect of contingencies," International Journal of Production Research, vol. 54, no. 8, pp. 2433-2448, 2016.

[46] K. K. Boyer and M. W. Lewis, "Competitive priorities: investigating the need for trade-offs in operations strategy," Production and Operations Management, vol. 11, no. 1, pp. 9-20, 2002.

[47] K. K. Boyer and M. Pagell, "Measurement issues in empirical research: improving measures of operations strategy and advanced manufacturing technology," Journal of Operations Management, vol. 18, no. 3, pp. 361-374, 2000.

[48] K. Ferdows and A. De Meyer, "Lasting improvements in manufacturing performance: in search of a new theory," Journal of Operations Management, vol. 9, no. 2, pp. 168-184, 1990.

[49] T. Greswell, S. Childe, and R. Maull, "Three manufacturing strategy archetypes-a framework for the UK aerospace industry," in Strategic Management of the Manufacturing Value Chain, pp. 53-60, Springer, Berlin, Germany, 1998.

[50] M. H. Small and M. M. Yasin, "Advanced manufacturing technology: implementation policy and performance," Journal of Operations Management, vol. 15, no. 4, pp. 349-370, 1997.

[51] Y. Du, M. Cui, and J. Su, "Implementation processes of online and offline channel conflict management strategies in manufacturing enterprises: a resource orchestration perspective," International Journal of Information Management, vol. 39, pp. 136-145, 2018.

[52] X. A. Koufteros, M. A. Vonderembse, and W. J. Doll, "Examining the competitive capabilities of manufacturing firms," Structural Equation Modeling: A Multidisciplinary Journal, vol. 9, no. 2, pp. 256-282, 2002.

[53] A. K. Glasmeier, "The Japanese Technopolis programme: high-tech development strategy or industrial policy in disguise?" International Journal of Urban and Regional Research, vol. 12, no. 2, pp. 268-284, 1988.

[54] C. J. C. Jabbour, E. Maria da Silva, E. L. Paiva, and F. C. Almada Santos, "Environmental management in Brazil: is it a completely competitive priority?" Journal of Cleaner Production, vol. 21, no. 1, pp. 11-22, 2012.

[55] S. Nallusamy, D. Sri Lakshmana Kumar, K. Balakannan, and P. S. Chakraborty, "MCDM tools application for selection of suppliers in manufacturing industries using AHP, Fuzzy Logic and ANN," International Journal of Engineering Research in Africa, vol. 19, pp. 130-137, 2016.

[56] B. Aquilani, C. Silvestri, A. Ruggieri, and C. Gatti, "A systematic literature review on total quality management critical success factors and the identification of new avenues of research," TQM Journal, vol. 29, no. 1, 2017.

[57] M. Treacy and F. Wiersema, The Discipline of Market Leaders: Choose Your Customers, Narrow Your Focus, Dominate Your Market, Addison-Wesley, Boston, MA, USA, 2007.

[58] G. Ingarao, "Manufacturing strategies for efficiency in energy and resources use: the role of metal shaping processes," Journal of Cleaner Production, vol. 142, pp. 2872-2886, 2017.

[59] S. Kotha and D. Orne, "Generic manufacturing strategies: a conceptual synthesis," Strategic Management Journal, vol. 10, no. 3, pp. 211-231, 1989.

[60] J.-H. Thun, "Empirical analysis of manufacturing strategy implementation," International Journal of Production Economics, vol. 113, no. 1, pp. 370-382, 2008.

[61] P. T. Ward, G. K. Leong, and K. K. Boyer, "Manufacturing proactiveness and performance," Decision Sciences, vol. 25, no. 3, pp. 337-358, 1994.

[62] R. M. Grant, "Analyzing resources and capabilities," Contemporary Strategic Analysis: Concepts, Techniques and Applications, pp. 93-122, Basil Blackwell, Cambridge, MA, USA, 1991.

[63] W. Skinner, "Manufacturing-missing link in corporate strategy," 1969.

[64] C. W. Craighead and J. Meredith, "Operations management research: evolution and alternative future paths," 
International Journal of Operations and Production Management, vol. 28, no. 8, 2008.

[65] V. Keršuliene, E. K. Zavadskas, and Z. Turskis, "Selection of rational dispute resolution method by applying new stepwise weight assessment ratio analysis (SWARA)," Journal of Business Economics and Management, vol. 11, no. 2, pp. 243-258, 2010.

[66] J. Strand, R. T. Carson, S. Navrud, A. Ortiz-Bobea, and J. R. Vincent, "Using the Delphi method to value protection of the Amazon rainforest," Ecological Economics, vol. 131, pp. 475-484, 2017.

[67] M. Gul and A. F. Guneri, "A fuzzy multi criteria risk assessment based on decision matrix technique: a case study for aluminum industry," Journal of Loss Prevention in the Process Industries, vol. 40, pp. 89-100, 2016.

[68] A. Karbassi Yazdi, T. Hanne, J. C. Osorio Gómez, and J. L. García Alcaraz, "Finding the best third-party logistics in the automobile industry: a hybrid approach," Mathematical Problems in Engineering, vol. 2018, Article ID 5251261, , 2018.

[69] A. K. Yazdi, "Designing a mathematical model for indicators of service quality in the tourism industry based on SERVQUAL and Rembrandt methods," International Journal of Productivity and Quality Management, vol. 15, no. 4, p. 511, 2015.

[70] W. Lee, S.-K. Rhee, and J. Oh, “The relationships between manufacturing strategy process, manufacturing-marketing integration, and plant performance: an empirical study of Korean manufacturers," Operations Management Research, vol. 7, no. 3-4, pp. 117-133, 2014.

[71] A. Rojo, M. Stevenson, F. J. L. Montes, and M. N. PerezArostegui, "Supply chain flexibility in dynamic environments," International Journal of Operations and Production Management, vol. 38, no. 3, 2018.

[72] G. Vessal, Z. Mardani, and M. Mollai, "Knowledge, attitudes, and perceptions of pharmacists to adverse drug reaction reporting in Iran," Pharmacy World \& Science, vol. 31, no. 2, pp. 183-187, 2009.

[73] P. Wang, Z. Zhu, and Y. Wang, "A novel hybrid MCDM model combining the SAW, TOPSIS and GRA methods based on experimental design," Information Sciences, vol. 345, pp. 27-45, 2016.

[74] K. Hawks, "What is reverse logistics," Reverse Logist. Mag.vol. 1, no. 1, 2006.

[75] K. W. Platts, J. F. Mills, M. C. Bourne, A. D. Neely, A. H. Richards, and M. J. Gregory, "Testing manufacturing strategy formulation processes," International Journal of Production Economics, vol. 56-57, pp. 517-523, 1998.

[76] G. Genta, M. Galetto, and F. Franceschini, "Product complexity and design of inspection strategies for assembly manufacturing processes," International Journal of Production Research, vol. 56, no. 11, pp. 4056-4066, 2018.

[77] P. Chatterjee, M. Yazdani, S. Chakraborty, D. Panchal, and S. Bhattacharyya, Advanced Multi-Criteria Decision Making for Addressing Complex Sustainability Issues, IGI Global, Hershey, PA, USA, 2019.

[78] P. Cooke and L. Leydesdorff, "Regional development in the knowledge-based economy: the construction of advantage," The Journal of Technology Transfer, vol. 31, no. 1, pp. 5-15, 2006.

[79] M. A. Noble, "Manufacturing strategy: testing the cumulative model in a multiple country context," Decision Sciences, vol. 26, no. 5, pp. 693-721, 1995.

[80] R. Kumar, H. Singh, and R. Chandel, "Exploring the key success factors of advanced manufacturing technology implementation in Indian manufacturing industry," Journal of Manufacturing Technology Management, vol. 29, no. 1, 2018.

[81] T. Schoenherr, D. Power, R. Narasimhan, and D. Samson, "Competitive capabilities among manufacturing plants in developing, emerging, and industrialized countries: a comparative analysis," Decision Sciences, vol. 43, no. 1, pp. 37-72, 2012.

[82] L. Berrah, V. Clivillé, J. Montmain, and G. Mauris, “The Contribution concept for the control of a manufacturing multi-criteria performance improvement," Journal of Intelligent Manufacturing, vol. 30, no. 1, pp. 47-58, 2019.

[83] M. A. Badri, D. Davis, and D. Davis, "Operations strategy, environmental uncertainty and performance: a path analytic model of industries in developing countries," Omega, vol. 28, no. 2, pp. 155-173, 2000.

[84] S. V. Novikov, "Strategic analysis of the development of high-technology manufacturing facilities," Russian Engineering Research, vol. 38, no. 3, pp. 198-200, 2018.

[85] J. R. X. Alves and J. M. Alves, "Production management model integrating the principles of lean manufacturing and sustainability supported by the cultural transformation of a company," International Journal of Production Research, vol. 53, no. 17, pp. 5320-5333, 2015.

[86] J. A. D. Machuca, C. H. Ortega Jiménez, P. Garrido-Vega, and J. L. P. D. de los Ríos, "Do technology and manufacturing strategy links enhance operational performance? Empirical research in the auto supplier sector," International Journal of Production Economics, vol. 133, no. 2, pp. 541-550, 2011.

[87] P. Garrido-Vega, C. H. Ortega Jimenez, J. L. D. P. de los Ríos, and M. Morita, "Implementation of technology and production strategy practices: relationship levels in different industries," International Journal of Production Economics, vol. 161, pp. 201-216, 2015.

[88] A. Karasan, M. Erdogan, and E. Ilbahar, "Prioritization of production strategies of a manufacturing plant by using an integrated intuitionistic fuzzy AHP \& TOPSIS approach," Journal of Enterprise Information Management, vol. 31, no. 4, 2018.

[89] G. K. Leong, D. L. Snyder, and P. T. Ward, "Research in the process and content of manufacturing strategy," Omega, vol. 18, no. 2, pp. 109-122, 1990.

[90] M. T. Frohlich and J. R. Dixon, "A taxonomy of manufacturing strategies revisited," Journal of Operations Management, vol. 19, no. 5, pp. 541-558, 2001.

[91] Y. P. Gupta and T. M. Somers, "Business strategy, manufacturing flexibility, and organizational performance relationships: a path analysis approach," Production and Operations Management, vol. 5, no. 3, pp. 204-233, 1996.

[92] T. Hill, Manufacturing Strategy: Text and Cases, Macmillan International Higher Education, London, UK, 1995.

[93] S. B. Ibrahim, A. Y. Abker, and T. K. Eltayeb, "The mediating role of service innovation in the relationship between strategic orientation and Operational flexibility in Sudanese service firms," Asian Journal of Management, vol. 9, no. 4, pp. 1221-1229, 2018.

[94] S. Biswas, "Measuring performance of healthcare supply chains in India: a comparative analysis of multi-criteria decision making methods," Decision Making: Applications in Management and Engineering, vol. 3, no. 2, pp. 162-189, 2020.

[95] A. A. Esfahani, H. Ahmadi, M. Nilashi et al., "An evaluation model for the implementation of hospital information 
system in public hospitals using multi-criteria-decisionmaking (MCDM) approaches," International Journal of Engineering and Technology, vol. 7, no. 1, pp. 1-18, 2018.

[96] D. Sumrit, "Understanding critical success factors of vendor-managed inventory in healthcare sector: a case study in Thailand," International Journal of Healthcare Management, pp. 1-12, 2019.

[97] Ž. Stević, D. Pamučar, A. Puška, and P. Chatterjee, "Sustainable supplier selection in healthcare industries using a new MCDM method: measurement of alternatives and ranking according to COmpromise solution (MARCOS)," Computers and Industrial Engineering, vol. 140, Article ID 106231, 2020.

[98] S. Emec, B. Turanoglu, S. Oztas, and G. Akkaya, "An integrated MCDM for a medical company selection in health sector," International Journal of Scientific \& Technology Research, 2019.

[99] M.-H. Chang, J. J. H. Liou, and H.-W. Lo, "A hybrid MCDM model for evaluating strategic alliance partners in the green biopharmaceutical industry," Sustainability, vol. 11, no. 15, p. 4065, 2019.

[100] A. A. Hasani and H. Mokhtari, Self-efficiency Assessment of Sustainable Dynamic Network Healthcare Service System under Uncertainty: Hybrid Fuzzy DEA-MCDM Method, Statistical Center of Iran, Tehran, Iran, 2020.

[101] A. K. Yazdi, T. Hanne, and J. C. Osorio Gómez, "Evaluating the performance of colombian banks by hybrid multicriteria decision making methods," Journal of Business Economics and Management, vol. 21, no. 6, p. 1707, 2020.

[102] X. Zhao, C.-C. Sum, Y. Qi, H. Zhang, and T.-S. Lee, "A taxonomy of manufacturing strategies in China," Journal of Operations Management, vol. 24, no. 5, pp. 621-636, 2006.

[103] J. Osborne, S. Collins, M. Ratcliffe, R. Millar, and R. Duschl, "What ?ideas-about-science? should be taught in school science? A Delphi study of the expert community," Journal of Research in Science Teaching, vol. 40, no. 7, pp. 692-720, 2003.

[104] A. L. Delbecq, A. H. Van de Ven, and D. H. Gustafson, Group Techniques for Program Planning: A Guide to Nominal Group and Delphi Processes, Scott Foresman, Northbrook, IL, USA, 1975.

[105] P.-T. Chang, L.-C. Huang, and H.-J. Lin, "The fuzzy Delphi method via fuzzy statistics and membership function fitting and an application to the human resources," Fuzzy Sets and Systems, vol. 112, no. 3, pp. 511-520, 2000.

[106] J. W. Murry Jr and J. O. Hammons, "Delphi: a versatile methodology for conducting qualitative research," The Review of Higher Education, vol. 18, no. 4, pp. 423-436, 1995.

[107] G. Thomas, How to Do Your Case Study, Sage Publications Limited, London, UK, 2021.

[108] R. K. Yin, "Case study methods," 2012.

[109] J. R. Feagin, A. M. Orum, and G. Sjoberg, A Case for the Case Study, UNC Press Books, Chapel Hill, NC, USA, 1991.

[110] R. K. Yin, "Discovering the future of the case study. Method in evaluation research," Evaluation Practice, vol. 15, no. 3, pp. 283-290, 1994.

[111] T. Tanino, "Sensitivity analysis in MCDM," in Multicriteria Decision Making, pp. 173-201, Springer, Berlin, Germany, 1999.

[112] D. Lee, I. Chang, H. Pham, and K. Song, "A software reliability model considering the syntax error in uncertainty environment, optimal release time, and sensitivity analysis," Applied Sciences, vol. 8, no. 9, p. 1483, 2018.
[113] E. Mulliner, N. Malys, and V. Maliene, "Comparative analysis of MCDM methods for the assessment of sustainable housing affordability," Omega, vol. 59, pp. 146-156, 2016.

[114] D. Pamučar and G. Ćirović, "The selection of transport and handling resources in logistics centers using Multi-Attributive Border Approximation area Comparison (MABAC)," Expert Systems with Applications, vol. 42, no. 6, pp. 3016-3028, 2015.

[115] E. Bakhtavar and S. Yousefi, "Assessment of workplace accident risks in underground collieries by integrating a multi-goal cause-and-effect analysis method with MCDM sensitivity analysis," Stochastic Environmental Research and Risk Assessment, vol. 32, no. 12, pp. 3317-3332, 2018.

[116] H. Barron and C. P. Schmidt, "Sensitivity analysis of additive multiattribute value models," Operations Research, vol. 36, no. 1, pp. 122-127, 1988.

[117] S. R. Watson, D. M. Buede, and D. M. Buede, Decision Synthesis: The Principles and Practice of Decision Analysis, Cambridge University Press, Cambridge, UK, 1987.

[118] A. Sharma, S. B. Borah, and A. C. Moses, "Responses to COVID-19: the role of governance, healthcare infrastructure, and learning from past pandemics," Journal of Business Research, vol. 122, pp. 597-607, 2021.

[119] D. Stanujkic, D. Karabasevic, and E. K. Zavadskas, "A framework for the selection of a packaging design based on the SWARA method," Inz. Ekon. Economics, vol. 26, no. 2, pp. 181-187, 2015.

[120] S. H. Zolfani, M. Yazdani, and E. K. Zavadskas, "An extended stepwise weight assessment ratio analysis (SWARA) method for improving criteria prioritization process," Soft Computing, vol. 22, no. 22, pp. 7399-7405, 2018.

[121] A. Valipour, N. Yahaya, N. Md Noor, J. Antuchevičienė, and J. Tamošaitienè, "Hybrid SWARA-COPRAS method for risk assessment in deep foundation excavation project: an Iranian case study," Journal of Civil Engineering and Management, vol. 23, no. 4, pp. 524-532, 2017.

[122] A. K. Yazdi, A. R. Komijan, P. F. Wanke, and S. Sardar, "Oil project selection in Iran: a hybrid MADM approach in an uncertain environment," Applied Soft Computing, vol. 88, Article ID 106066, 2020.

[123] H. Sadoghi Yazdi, R. Pourreza, and M. Sadoghi Yazdi, "Constraint learning using adaptive neural-fuzzy inference system," International Journal of Intelligent Computing and Cybernetics, vol. 3, no. 2, pp. 257-278, 2010.

[124] A. K. Yazdi, P. F. Wanke, T. Hanne, and E. Bottani, “A decision-support approach under uncertainty for evaluating reverse logistics capabilities of healthcare providers in Iran," Journal of Enterprise Information Management, vol. 33, no. 5, 2020.

[125] C. Powell, "The Delphi technique: myths and realities," Journal of Advanced Nursing, vol. 41, no. 4, pp. 376-382, 2003.

[126] R. B. Dunham, The DELPHI Technique, Organizational Behavior and Human Decision Processes, Gibson, Australia, 1998.

[127] A. Presley, L. Meade, and J. Sarkis, “A strategic sustainability justification methodology for organizational decisions: a reverse logistics illustration," International Journal of Production Research, vol. 45, no. 18-19, pp. 4595-4620, 2007.

[128] M. Kamali et al., "Prevalence and antibiotic resistance of Acinetobacter baumannii among patients in postcardiac surgery intensive care units of Rajaei Hospital, Tehran," Medical Journal of the Islamic Republic of Iran, vol. 34, no. 4, 2020 . 
[129] S. Siami-Namini, The New Public Management: Administrative Reform in Iran, 2020.

[130] K. Parveen, K. Hussain, M. Afzal, and S. A. Gilani, "Determining the association of high-commitment human resource practices with nurses' compassionate care behaviour: a cross-sectional investigation," Journal of Nursing Management, vol. 28, no. 1, pp. 120-129, 2020.

[131] R. Sharma, A. Sinha, and P. Kautish, "Does renewable energy consumption reduce ecological footprint? Evidence from eight developing countries of Asia," Journal of Cleaner Production, vol. 285, Article ID 124867, 2021.

[132] A. Kumari, N. S. Maurya, and B. Tiwari, "Hospital wastewater treatment scenario around the globe," in Current Developments in Biotechnology and Bioengineering, pp. 549-570, Elsevier, Amsterdam, Netherlands, 2020. 